\title{
Erratum to: clinical comparison of the effectiveness of 7- and 14-day intracanal medications in root canal disinfection and inflammatory cytokines
}

\author{
Frederico C. Martinho ${ }^{1}$ - Cinthya C. Gomes ${ }^{2}$ - Gustavo G. Nascimento ${ }^{3}$.
}

Ana P. M. Gomes ${ }^{1} \cdot$ Fábio R. M. Leite ${ }^{3}$

Published online: 7 July 2017

(C) Springer-Verlag GmbH Germany 2017

Erratum to: Clinical Oral Investigations

DOI 10.1007/s00784-017-2143-x

In the original version of this article, the name of Gustavo G.

Nascimento was incorrectly presented as Gustavo N.

Nascimento.

The original article was corrected.

The online version of the original article can be found at http://dx.doi.org/ 10.1007/s00784-017-2143-x

Frederico C. Martinho

Frederico.martinho@fosjc.unesp.br

1 Department of Restorative Dentistry, Endodontic Division, São José dos Campos Dental School, State University of São Paulo - UNESP, Eng Francisco José Longo, 777, São José dos Campos, São Paulo CEP 12245-000, Brazil

2 Department of Restorative Dentistry, Endodontic Division, Fluminense Federal University (UFF), Nova Friburgo, RJ, Brazil

3 Department of Semiology, School of Dentistry, Federal University of Pelotas, Pelotas, RS, Brazil 